\title{
Incidence of Dementia and Cognitive Impairment, Not Dementia in the United States
}

\author{
Brenda L. Plassman, PhD, ${ }^{1}$ Kenneth M. Langa, MD, PhD, ${ }^{2,3,4}$ Ryan J. McCammon, BA, ${ }^{2}$ \\ Gwenith G. Fisher, PhD, ${ }^{4}$ Guy G. Potter, PhD, ${ }^{1}$ James R. Burke, MD, PhD, ${ }^{5,6}$ \\ David C. Steffens, MD, MHS, ${ }^{1}$ Norman L. Foster, MD, ${ }^{7}$ Bruno Giordani, PhD, ${ }^{8}$ \\ Frederick W. Unverzagt, PhD, ${ }^{9}$ Kathleen A. Welsh-Bohmer, PhD, ${ }^{1,6}$ \\ Steven G. Heeringa, PhD, ${ }^{4}$ David R. Weir, PhD, ${ }^{4}$ and Robert B. Wallace, MD, MSc ${ }^{10}$
}

\begin{abstract}
Objective: Estimates of incident dementia, and cognitive impairment, not dementia (CIND) (or the related mild cognitive impairment) are important for public health and clinical care policy. In this paper, we report US national incidence rates for dementia and CIND.

Methods: Participants in the Aging, Demographic, and Memory Study (ADAMS) were evaluated for cognitive impairment using a comprehensive in-home assessment. A total of 456 individuals aged 72 years and older, who were not demented at baseline, were followed longitudinally from August 2001 to December 2009. An expert consensus panel assigned a diagnosis of normal cognition, CIND, or dementia and its subtypes. Using a populationweighted sample, we estimated the incidence of dementia, Alzheimer disease (AD), vascular dementia (VaD), and CIND by age. We also estimated the incidence of progression from CIND to dementia.

Results: The incidence of dementia was 33.3 (standard error [SE], 4.2) per 1,000 person-years and 22.9 (SE, 2.9) per 1,000 person-years for AD. The incidence of CIND was 60.4 (SE, 7.2) cases per 1,000 person-years. An estimated 120.3 (SE, 16.9) individuals per 1,000 person-years progressed from CIND to dementia. Over a 5.9-year period, about 3.4 million individuals aged 72 and older in the United States developed incident dementia, of whom approximately 2.3 million developed $A D$, and about 637,000 developed $\mathrm{VaD}$. Over this same period, almost 4.8 million individuals developed incident CIND.

Interpretation: The incidence of CIND is greater than the incidence of dementia, and those with CIND are at high risk of progressing to dementia, making CIND a potentially valuable target for treatments aimed at slowing cognitive decline.
\end{abstract}

ANN NEUROL 2011;70:418-426

$T_{\mathrm{U}}^{\mathrm{h}}$ he rapid growth in the number of older adults in the United States puts an increasing number of individuals at risk for cognitive impairment and dementia. As a result of this demographic shift in the population, the prevalence of Alzheimer disease (AD) is estimated to grow to nearly 9 million individuals in North America by $2050 .{ }^{1}$ Previous estimates of the incidence of dementia and $\mathrm{AD}$ in the United States for individuals aged 65 years and older primarily have been extrapolated from data on local or regional samples. These estimates range from 20 to 43 cases per 1,000 person-years for dementia ${ }^{2-6}$ and from 14 to 27 cases per 1,000 person-years for $\mathrm{AD} .^{2-3,5,7,8}$

Fewer estimates are available for the incidence of milder impairment that does not reach the severity of

View this article online at wileyonlinelibrary.com. DOI: 10.1002/ana.22362

Received Jul 26, 2010, and in revised form Nov 10, 2010. Accepted for publication Dec 17, 2010.

Address correspondence to Dr Plassman, 905 W. Main Street, Ste 25-D, Box 41, Duke University Medical Center, Durham, NC 27701.

E-mail: brenda.plassman@duke.edu

From the ${ }^{1}$ Department of Psychiatry and Behavioral Sciences, Duke University Medical Center, Durham, NC; ${ }^{2}$ Division of General Medicine, Department of Medicine, University of Michigan, Ann Arbor, Ml; ${ }^{3}$ Veterans Affairs Center for Practice Management and Outcomes Research, Ann Arbor, Ml; ${ }^{4}$ Institute for Social Research, University of Michigan, Ann Arbor, Ml; ${ }^{5}$ Department of Medicine (Neurology), Duke University Medical Center, Durham, NC; ${ }^{6}$ oseph and Kathleen Bryan Alzheimer's Disease Research Center, Durham, NC; ${ }^{7}$ Center for Alzheimer's Care, Imaging, and Research, Department of Neurology, Center on Aging and the Brain Institute, University of Utah, Salt Lake City, UT; ${ }^{8}$ Departments of Psychiatry, Neurology, and Psychology, University of Michigan, Ann Arbor, MI; ${ }^{9}$ Department of Psychiatry, Indiana University School of Medicine, Indianapolis, IN; ${ }^{10}$ Colleges of Public Health and Medicine, University of lowa, lowa City, IA 
dementia, often termed mild cognitive impairment (MCI) or cognitive impairment, not dementia (CIND). The criteria for CIND and MCI have grown more similar over time, ${ }^{9}$ with the 1 remaining difference being that CIND requires either complaint of a problem or impaired test performance, ${ }^{10}$ and MCI requires both complaint of a problem and impaired test performance. ${ }^{11}$ This difference in criteria for CIND and MCI does not appear to account for the broad variability in estimated incidence rates for mild impairment, ${ }^{12}$ which range from 22 to 51 cases per 1,000 person-years. ${ }^{13-15}$ Although incidence estimates for MCI and CIND vary, there is general agreement that individuals with cognitive impairment are at higher risk of progressing to dementia compared to older individuals with normal cognition.

Estimates of the incidence of CIND and dementia are essential to provide benchmarks against which to assess trends in incidence rates over time and to assess the effect of preventative measures devoid of survival effects that can bias prevalence estimates. Both the large numbers of individuals affected with CIND or dementia and the conditions' broad impact on the individual's health, family resources, and healthcare mean that even small benefits from future interventions may have a significant impact on disease burden in the United States.

The Aging, Demographics, and Memory Study (ADAMS) uses a national probability sample that includes individuals from all regions of the United States and provides a unique resource to estimate incidence rates for dementia, AD, and CIND. As a longitudinal study, it is also able to assess rates of progression from CIND to dementia and better identify the full implications of cognitive impairment for public health and clinical care policy.

\section{Subjects and Methods \\ Sample}

The ADAMS sample was drawn from the larger Health and Retirement Study (HRS), an ongoing national probability cohort study of individuals born prior to 1960 , designed to investigate the health, social, and economic implications of the aging of the American population. ${ }^{16-18}$ The HRS began in 1992, and the current sample includes approximately 22,000 individuals.

The ADAMS began with a stratified random subsample of 1,770 individuals from the approximately 7,000 HRS respondents aged $\geq 70$ years old who completed the 2000 or 2002 wave of HRS. Participants in the full ADAMS sample lived in 42 states distributed throughout all census regions of the United States. To achieve a sufficient number of ADAMS respondents across the full range of cognitive ability, the sample was stratified based on cognitive screening scores on the HRS. Respondents were each classified into 1 of 5 cognitive strata, ranging from low to high cognition based on their HRS cogni- tive screening scores. For respondents who completed the HRS interview themselves, the score from an abbreviated version of the modified Telephone Interview for Cognitive Status ${ }^{19}$ was used to assign them to a stratum. For respondents unable to complete the interview themselves, a proxy for the respondent completed the Informant Questionnaire on Cognitive Decline in the Elderly (IQCODE), ${ }^{20}$ which assessed changes in the respondent's cognitive and functional ability. These respondents were classified based on the IQCODE scores. The highest 3 cognitive strata were further stratified by age (70-79 years vs $\geq 80$ years) and sex, to ensure adequate numbers in each subgroup. Additional details of the ADAMS sample design are described elsewhere. ${ }^{21,22}$

The Figure summarizes the number of participants at each phase of the study; additional details on participation rates have been reported previously. ${ }^{22}$ The initial ADAMS assessments (Wave A) were conducted from 2001 to 2003 and occurred on average 13.3 (standard deviation [SD], 6.9) months after the HRS interview. Three waves of follow-up assessments have been conducted on this sample. For the first follow-up wave (Wave B), a subset of ADAMS participants (see Fig) was selected to undergo an assessment approximately 16 to 18 months after the initial assessment if: (1) they received an initial diagnosis of cognitive impairment without dementia; or (2) they received an initial diagnosis of normal or demented, but the consensus diagnostic panel thought the initial assessment findings were ambiguous and longitudinal follow-up would help clarify the diagnosis. A second follow-up (Wave C) was done beginning in 2006 among the living participants not previously diagnosed with dementia in the ADAMS. The Wave C assessment took place on average 3.69 (range, 1.25-6.00) years after the participant's prior ADAMS assessment. Finally, beginning in 2008, the third follow-up (Wave D) was conducted an average of 1.8 years (range, 1.25-6.50) after the most recent assessment. The assessment protocols for the initial and follow-up assessments were similar, with only minor modifications in the assessment measures. The sample for the present analyses includes 456 individuals, spanning 36 states, who participated in the first wave (Wave A) of ADAMS data collection and who were not diagnosed with dementia at that wave.

All ADAMS data are publicly available and can be obtained from the HRS website. ${ }^{23}$ The institutional review boards at Duke University Medical Center and the University of Michigan approved all study procedures, and study participants or their surrogates provided informed consent.

\section{Dementia Assessment and Diagnosis}

All participants were assessed for cognitive impairment in-person in their residence by a nurse and neuropsychology technician. The full details of these assessment and diagnostic procedures have been previously described. ${ }^{22}$ Briefly, an informant (usually a spouse or adult child) was identified by the respondent as someone who was knowledgeable about the respondent's daily activities and health issues. The following information about the respondent was collected from the informant: (1) a detailed chronological history of cognitive and functional 


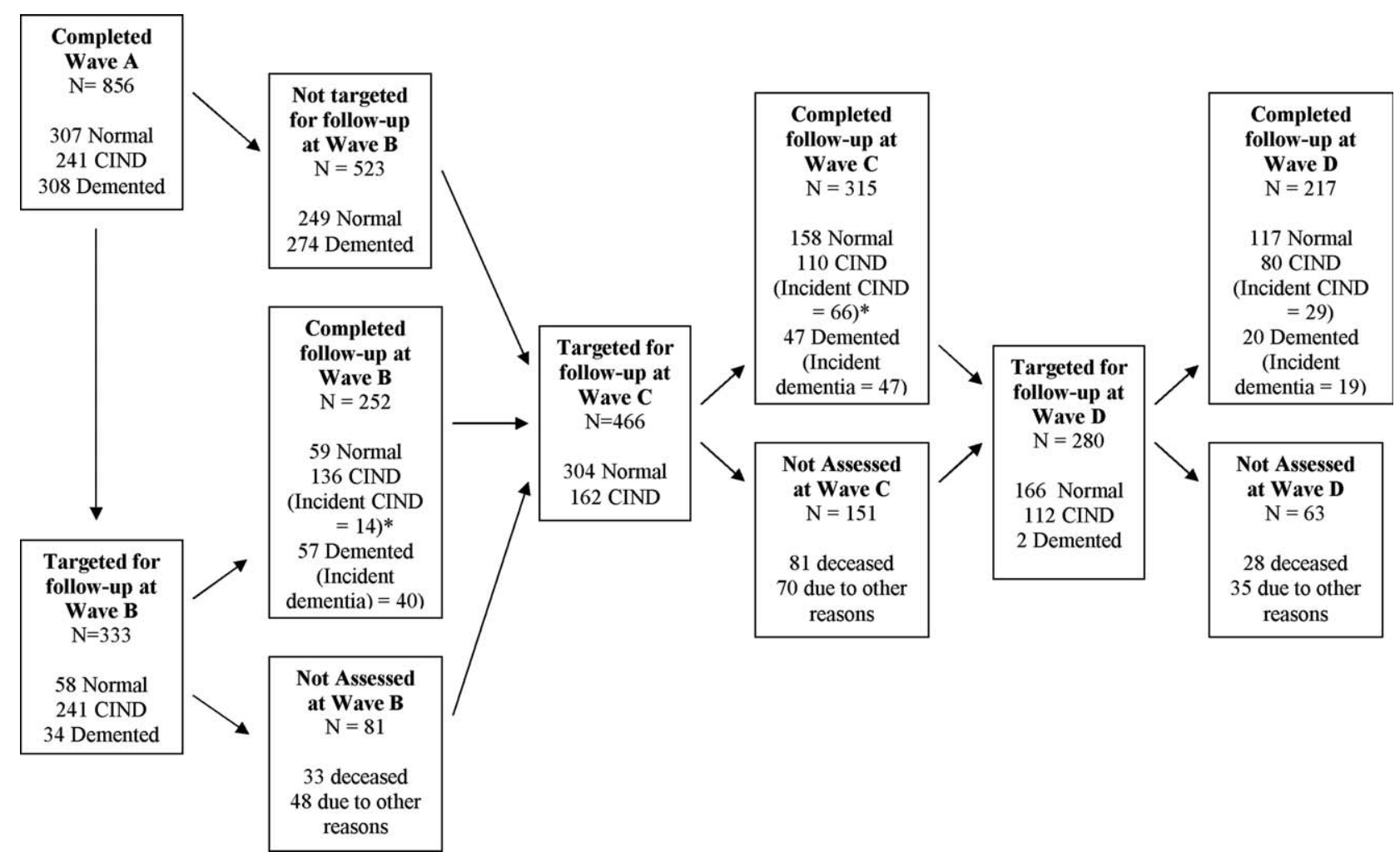

FIGURE: Flowchart of number of participants at each phase of the study. *Includes 16 incident cognitive impairment, not dementia (CIND) cases excluded from incidence analysis because of nonresponse (part of the cases not assessed at Wave $C$ and/ or Wave D "due to other reasons").

symptoms, (2) medical history, (3) current medications, (4) current neuropsychiatric symptoms, (5) measures of severity of cognitive and functional impairment, and (6) family history of memory problems. During the assessment, each respondent completed: (1) a battery of neuropsychological measures, (2) a self-report depression measure, (3) a standardized neurological examination, (4) a blood pressure measure, (5) collection of buccal DNA sample for $A P O E$ genotyping, and (6) a 7-minute videotaped segment covering portions of the cognitive status and neurological examinations. The neuropsychological battery has been described elsewhere, ${ }^{22}$ and included measures of orientation, verbal and visual immediate and delayed memory, language, attention, executive function, praxis, and reading ability. Medical record releases were also sought to obtain relevant prior neuroimaging and laboratory results from participants' physicians.

Final diagnoses were assigned by a consensus expert panel made up of neuropsychologists, a cognitive neuroscientist, neurologists, geropsychiatrists, and internists. The consensus panel reviewed all information collected during the in-home assessment and assigned a diagnosis in 2 stages, first without the medical records and then with the medical records. As part of the consensus process, the panel compared performance on the neuropsychological tests from all assessments, but the consensus panel was blind to the cognitive diagnosis assigned at the previous assessments. All individuals involved in the clinical assessments or diagnosis of ADAMS participants were blind to the participants' HRS cognitive screening scores.
Diagnoses fell within the 3 general categories: normal cognitive function, CIND, and dementia. The dementia diagnosis was anchored by the Diagnostic and Statistical Manual of Mental Disorders (DSM)-III- $\mathrm{R}^{24}$ and DSM-IV ${ }^{25}$ criteria, but the final diagnosis was based on the clinical judgment of the consensus panel. Currently accepted diagnostic criteria were used for $\mathrm{AD}^{26}$ and vascular dementia $(\mathrm{VaD})$, as adapted for research studies. ${ }^{27}$ These assessment and diagnostic procedures for $\mathrm{AD}$ have been validated against neuropathological diagnoses. ${ }^{28}$

The criteria for CIND are less well-established than the criteria for dementia. In the ADAMS, the diagnosis of CIND was determined by clinical judgment, but was anchored in the following guidelines: cognitively not normal but not demented; self and/or informant report of problems with cognition or daily activities; or performance on neuropsychological measures that was both below expectation relative to education, reading level, and occupational attainment, and at least 1.5 SDs below published norms on at least 1 test. These CIND criteria are similar to those currently used for MCI, ${ }^{11}$ except that the latter require both self and/or informant complaint and impairment on neuropsychological measures.

To reflect that dementia and CIND are often the consequence of $>1$ pathological process, when appropriate we assigned a primary and secondary diagnosis denoting these multiple etiologies. Dementia onset was estimated as the age at which the individual met criteria for dementia based on a systematic review of the chronological history of cognitive and functional changes. 


\section{Analyses}

Population sample weights were constructed to take into account the probabilities of selection in the stratified longitudinal sample design and to adjust for differential participation in ADAMS at each assessment wave. Details of the development of these weights are described in a technical report elsewhere. ${ }^{21}$ We compared sample characteristics by final cognitive status using the Wald chi-square test for categorical measures and the $t$ test for continuous measures. Using the ADAMS sample weights, we estimated the national incidence of CIND and dementia (as well as the dementia subtypes $\mathrm{AD}$ and $\mathrm{VaD}$ ) as the number of individuals affected per 1,000 person-years by 8 - or 10 -year age at follow-up categories.

To examine possible predictors of incident cognitive impairment reported in other studies, we used logistic regression to estimate the likelihood of dementia, AD, and CIND first as a function of age and then as a function of age and each of the following variables individually: education, gender, race, and $A P O E$ genotype. We then created models with all of the variables included. The results for each of the variables in the full models were similar to those for the reduced models, so we report only the full models in the Results section. For the estimation of incidence rates, person-years were calculated for each case as the number of years from the baseline assessment until the first of any of the following events: (1) the event of interest (dementia onset, for example), (2) death, or (3) completion of the final follow-up assessment (Wave D).

All analyses were conducted in SAS version 9.2 (SAS Institute, Cary, NC) using procedures that account for the influence of the weighting and other complex sample design features.

\section{Results}

The Figure shows the number of individuals in each outcome category for each phase of the study. Table 1 provides sample characteristics of individuals based on cognitive status at follow-up. Individuals who did not participate at Wave C or Wave D $(n=92)$ due to illness, refusal, or being unable to be located did not differ from participants on baseline age, years of education, $A P O E$ e4 allele status, or mean Mini-Mental State Examination score; but they did differ on ethnicity, in that Hispanics made up $11.6 \%$ of nonparticipants but only $4.1 \%$ of participants. Participants were followed an average of 4.89 (SD, 1.76) years. The mean estimated age of onset for incident dementia was 83.72 years (SD, 5.49), and the estimated mean age at first diagnosis for those with incident CIND was 82.83 years (SD, 5.35).

Table 2 shows rates of incident CIND, AD, and dementia by age at follow-up. The incidence of dementia increased progressively with age, reaching 82 cases per 1,000 person-years for individuals aged $>90$ years. AD incidence also increased with age and accounted for
$>70 \%$ of the dementia cases overall. The incidence of $\mathrm{VaD}(\mathrm{n}=16)$ overall was 6.2 (95\% confidence interval [CI], 1.7-10.7) cases per 1,000 person-years. VaD incidence increased from 2.1 (95\% CI, 0.0-4.9) cases per 1,000 person-years for those aged 72 to 79 years to 11.4 (95\% CI, 1.9-20.9) for those aged 80 to 89 years; however, there were no additional cases of vascular dementia for those aged 90 and older. Overall, we found that an estimated 3.4 million individuals aged 72 and older in the United States developed incident dementia over a follow-up period of 5.9 years, of whom approximately 2.3 million developed $\mathrm{AD}$ and 636,825 developed $\mathrm{VaD}$.

Table 2 also shows that the incidence of CIND progressively increased with age, and at each age stratum the incidence of CIND was higher than the incidence of dementia. When limiting the analyses just to those with CIND, the incidence rate at which individuals with CIND progressed to dementia was 120.3 cases per 1,000 person-years. In contrast, the incidence rate of conversion to dementia among those with normal cognition was 17.1 cases per 1,000 person-years, a rate $7 \times$ lower than among the CIND group. Even so, it is important to note that among the 214 individuals with CIND at baseline who were followed longitudinally, 110 retained their CIND designation throughout the period that they were followed, which suggests that progression to dementia may not be inevitable among individuals in this group. Twenty-five individuals (11.7\%) with CIND at baseline reverted to normal cognition at a subsequent follow-up assessment, but 15 of these 25 then later reverted back to CIND, and 5 individuals progressed to dementia after further longitudinal follow-up. Over an average followup period of 4.8 years, an estimated 4.8 million individuals aged 72 and older in the United States developed incident CIND. Based on these national estimates, individuals who progress from CIND to dementia account for $75 \%$ of all incident cases of dementia.

Table 3 shows the results of the full logistic models predicting dementia, AD, and CIND. Older age and fewer years of education tended to be associated with a higher risk of $\mathrm{AD}$ and dementia among all participants; the odds ratios for the 3 cognitive outcomes were similar, but only some of the values reached standard significance levels. The presence of at least 1 APOE e4 allele was associated with increased risk of incident dementia, AD, and CIND. There was no significant association between race and the incidence of CIND, dementia or $\mathrm{AD}$ among all participants, whereas being male was associated with decreased risk of AD.

When limiting the group to those with CIND, males had a lower risk of progressing to dementia than 


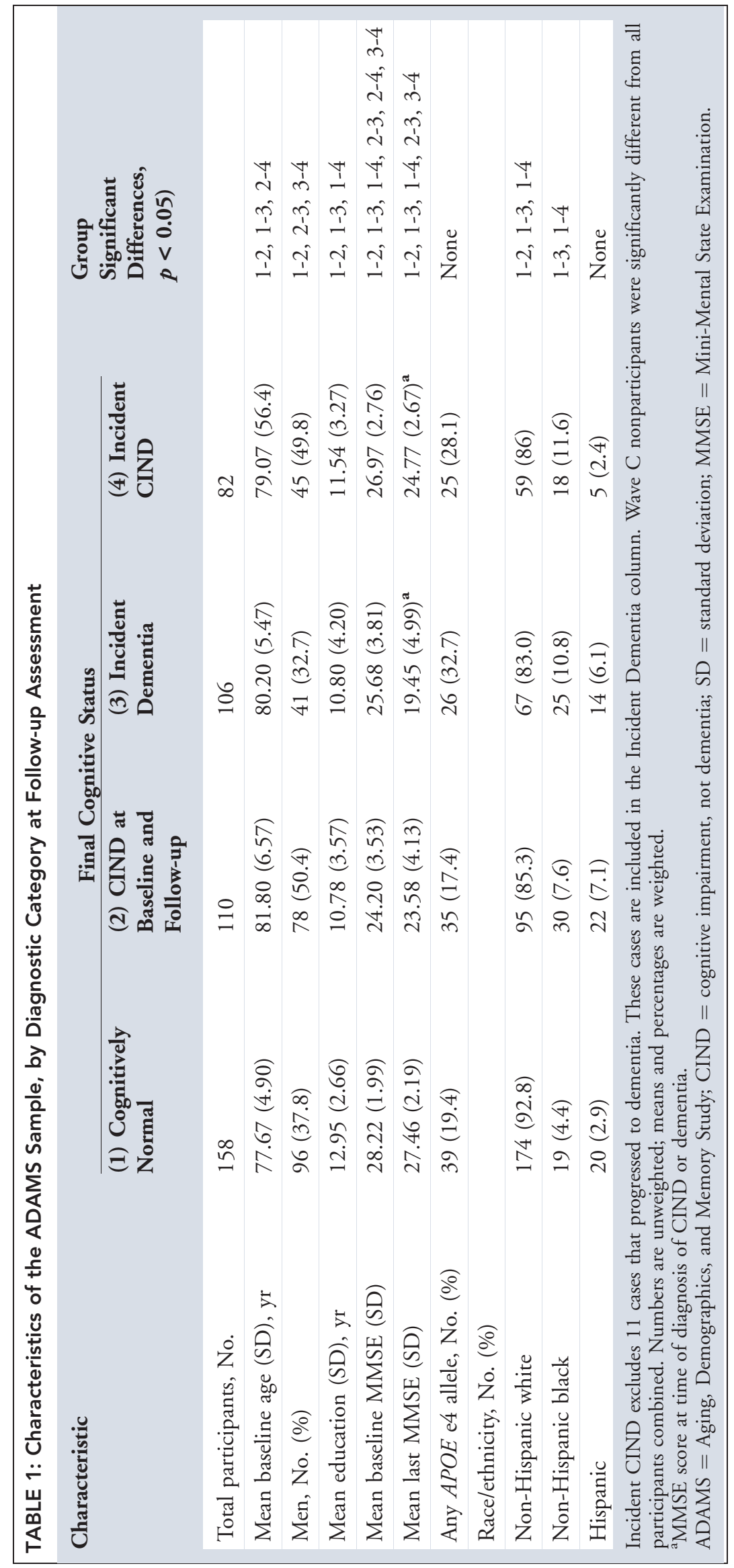




\begin{tabular}{|c|c|c|c|c|c|c|}
\hline $\begin{array}{l}\text { Incident } \\
\text { Condition }\end{array}$ & $\begin{array}{l}\text { Age } \\
\text { Group, } \\
\text { yr }\end{array}$ & $\begin{array}{l}\text { ADAMS Sample } \\
\text { Incident Cases, } \\
\text { Unweighted }\end{array}$ & $\begin{array}{l}\text { Estimate of } \\
\text { Population } \\
\text { Incident Cases }\end{array}$ & $\begin{array}{l}\text { Population } \\
\text { Person-Years }\end{array}$ & $\begin{array}{l}\text { Estimate of } \\
\text { Incidence/ } 1,000 \\
\text { Person-Years (SE) }\end{array}$ & $\begin{array}{l}\text { Incidence/1,000 } \\
\text { Person-Years, } \\
95 \% \text { CI }\end{array}$ \\
\hline \multirow[t]{4}{*}{ Dementia } & $72-79$ & 22 & 938,949 & $49,574,616$ & $18.9(4.3)$ & $10.1-27.8$ \\
\hline & $80-89$ & 58 & $1,965,362$ & $46,528,062$ & $42.2(7.9)$ & $26.0-58.5$ \\
\hline & $90+$ & 26 & 503,009 & $6,127,925$ & $82.1(20.5)$ & $39.9-124.3$ \\
\hline & Total & 106 & $3,407,320$ & $102,230,604$ & $33.3(4.2)$ & $24.7-42.0$ \\
\hline \multirow[t]{4}{*}{$\mathrm{AD}$} & $72-79$ & 16 & 821,592 & $49,574,616$ & $16.6(4.2)$ & $8.0-25.1$ \\
\hline & $80-89$ & 39 & $1,127,323$ & $46,528,062$ & $24.2(4.5)$ & $15.0-33.4$ \\
\hline & $90+$ & 22 & 392,057 & $6,127,925$ & $64.0(15.7)$ & $31.8-96.2$ \\
\hline & Total & 77 & $2,340,972$ & $102,230,604$ & $22.9(2.9)$ & $17.0-28.8$ \\
\hline \multirow[t]{4}{*}{ CIND } & $72-79$ & 38 & $1,653,503$ & $42,034,445$ & $39.3(8.2)$ & $22.5-56.2$ \\
\hline & $80-89$ & 45 & $2,538,220$ & $34,701,193$ & $73.1(11.8)$ & $48.8-97.5$ \\
\hline & $90+$ & 10 & 630,925 & $3,057,444$ & $206.4(56.1)$ & $91.1-321.6$ \\
\hline & Total & 93 & $4,822,649$ & $79,793,083$ & $60.4(7.2)$ & $45.6-75.3$ \\
\hline \multirow[t]{4}{*}{$\begin{array}{l}\text { Dementia } \\
\text { (among CIND) }\end{array}$} & $72-79$ & 19 & 741,835 & $7,253,899$ & $102.3(21.8)$ & $57.5-147.0$ \\
\hline & $80-89$ & 50 & $1,474,533$ & $10,988,270$ & $123.8(26.5)$ & $679.3-178.4$ \\
\hline & $90+$ & 21 & 341,135 & $2,737,281$ & $124.6(35.6)$ & $51.4-197.8$ \\
\hline & Total & 90 & $2,557,503$ & $21,259,407$ & $120.3(16.9)$ & $85.6-155.0$ \\
\hline \multicolumn{7}{|c|}{$\begin{array}{l}\text { Total sample size for incident dementia and } \mathrm{AD} \text { analyses }=456 \text {; total sample size for incident CIND analysis }=266 \text {; total sample } \\
\text { size for incident dementia among CIND group = } 268 \text {; total sample size for incident dementia from normal group }=242 \text {. } \\
\text { Number of incident CIND is } 11 \text { more than in Table } 1 \text { because Table } 2 \text { numbers for incident CIND include the } 11 \text { individuals } \\
\text { who developed incident CIND and then progressed to incident dementia. } \\
\mathrm{AD}=\text { Alzheimer disease; CIND = cognitive impairment, not dementia; } \mathrm{SE}=\text { standard error; } \mathrm{CI}=\text { confidence interval. }\end{array}$} \\
\hline
\end{tabular}

females (odds ratio [OR], 0.59; 95\% CI, 0.36-0.97) (see Table 3). The association between APOE e4 carriers and progression to dementia was significant (OR, 2.76; 95\% CI, 1.27-5.97). Age, education, and race were not associated with progression from CIND to dementia.

\section{Discussion}

We estimate that about 3.4 million new cases of dementia occur during 6 years of follow-up for a US cohort that is aged $72+$ years at baseline; approximately 2.3 million of these individuals have AD. Almost 4.8 million individuals are estimated to develop incident CIND during the same time period, which is approximately $40 \%$ more than the number of incident dementia cases of $\mathrm{AD}$ in this age group in the United States. These are the first estimates of the incidence of $\mathrm{AD}$, dementia, and CIND in a national probability US sample. Direct comparisons to other studies of dementia and $\mathrm{AD}$ incidence estimates are difficult due to differences in the age structure of the samples and the reporting of different age strata among the various studies. However, estimates of the incidence of dementia and AD from ADAMS are broadly within the midrange of estimates reported by other studies in the United States and Canada. ${ }^{2-7,29}$ We note that the other studies used age 65 years as the lower limit; ADAMS incidence rates would likely have been lower if its age range were lowered from 72 to 65 years. Brookmeyer and colleagues ${ }^{1}$ developed an equation for age-specific AD incidence rates based on a review of the worldwide literature. Applying this equation to US 2004 life tables, ${ }^{30}$ the estimated incidence of $\mathrm{AD}$ for ages 72 to 79 years would be 8.5 cases per 1,000 person-years, 25.6 cases per 1,000 person-years for ages 80 to 89 years, and 


\begin{tabular}{|c|c|c|c|c|}
\hline Characteristic & $\begin{array}{l}\text { Dementia, } \\
\text { OR }(95 \%)\end{array}$ & $\begin{array}{l}\mathrm{AD}, \mathrm{OR} \\
(95 \%)\end{array}$ & $\begin{array}{l}\text { CIND, OR } \\
(95 \%)\end{array}$ & $\begin{array}{l}\text { Dementia } \\
\text { from CIND, OR }(95 \%)\end{array}$ \\
\hline Baseline age & $1.05(1.00-1.12)$ & $1.04(0.99-1.11)$ & $1.06(1.00-1.14)^{\mathrm{a}}$ & $1.01(0.95-1.07)$ \\
\hline Years of schooling & $0.89(0.82-0.96)^{\mathbf{a}}$ & $0.89(0.81-0.98)^{\mathbf{a}}$ & $0.86(0.77-0.97)^{\mathbf{a}}$ & $0.99(0.91-1.08)$ \\
\hline \multicolumn{5}{|l|}{ Gender } \\
\hline Male & $0.69(0.39-1.21)$ & $0.37(0.15-0.94)^{\mathbf{a}}$ & $1.64(0.84-3.19)$ & $0.59(0.36-0.97)^{\mathbf{a}}$ \\
\hline Female (ref) & 1.00 & 1.00 & 1.00 & 1.00 \\
\hline \multicolumn{5}{|l|}{ Race } \\
\hline Black & $0.98(0.50-1.95)$ & $1.22(0.58-2.57)$ & $1.67(0.78-3.57)$ & $1.45(0.59-3.56)$ \\
\hline Nonblack (ref) & 1.00 & 1.00 & 1.00 & 1.00 \\
\hline \multicolumn{5}{|c|}{ Any $A P O E$ E4 alleles } \\
\hline Yes & $2.20(1.09-4.44)^{\mathbf{a}}$ & $2.93(1.68-5.13)^{\mathbf{c}}$ & $2.65^{\mathbf{b}}(1.27-5.56)$ & $2.76(1.27-5.97)^{\mathbf{a}}$ \\
\hline No & 1.00 & 1.00 & 1.00 & 1.00 \\
\hline $\begin{array}{l}{ }^{\mathrm{a}} p \leq 0.05 \\
\mathrm{~b} p \leq 0.001 \\
\mathrm{c} p \leq 0.01 \\
\mathrm{AD}=\text { Alzheimer di } \\
\text { reference. }\end{array}$ & & & -00 & der \\
\hline
\end{tabular}

76.7 cases per 1,000 person-years for those aged 90 years and older. ${ }^{1}$ Although these estimated incidence rates are remarkably close to those found in ADAMS for individuals aged 80 years and older, the $\mathrm{AD}$ incidence rates from ADAMS for ages 72 to 79 years are higher than those estimated by the Brookmeyer equation. Notably, however, this is the age group in which the literature review $^{1}$ found the most heterogeneity among estimates worldwide and in which the US estimates were generally among the highest worldwide.

Few studies worldwide and even fewer US studies have estimated the incidence of mild impairment, labeled as either CIND or MCI. Differences in case ascertainment and diagnostic criteria make it difficult to compare studies, but our estimate of 60 cases per 1,000 personyears is slightly higher than 1 other multiethnic US study. ${ }^{14}$ Although most studies report an increased risk of dementia among those with various forms of mild cognitive impairment, the estimates of rates of progression have varied widely. One study compared rates of progression for 16 different diagnostic definitions of mild impairment and found that the rates of progression to dementia over 2 years ranged from $0.3 \%$ to $29 \%{ }^{31}$ Generally the definitions that allowed for impairment in both memory and nonmemory domains, similar to that used in the present study, resulted in the highest rates of conversion to dementia. We found that individuals who progressed from CIND accounted for $75 \%$ of the inci- dent dementia cases. It is likely that for many of the other $25 \%$ of incident dementia cases, we may have been able to detect CIND prior to dementia with shorter follow-up intervals. These findings highlight that a period of mild impairment prior to dementia is likely detectable in the majority of individuals. A point that is often overlooked is that many individuals remain mildly impaired for years and may not progress to dementia. Over $50 \%$ of individuals with CIND in the present study did not progress to dementia during the time period that they were followed. From this group, we may be able to identify factors that delay progression to dementia. It has been estimated that delaying the onset of $\mathrm{AD}$ by 1 year in those at risk would result in about 1 million fewer cases by $2050,{ }^{1}$ with the largest decrease in the number of severe $\mathrm{AD}$ cases. So interventions, whether behavioral or pharmaceutical, that can even modestly delay progression from CIND to dementia may significantly decrease the burden of dementia on patients, families, and the health system.

One of the challenges of studying the outcomes of mild impairment has been the variable rates of diagnostic stability over time, regardless of the diagnostic nomenclature used. In our sample, $12 \%$ of those with CIND reverted to normal cognition at 1 of the follow-up assessments. This rate of reversion to normal is virtually identical to that in another study ${ }^{32}$ that has used the same assessment and diagnostic procedures used in ADAMS. 
In a study ${ }^{31}$ that examined 2-year follow-up outcomes using 16 different algorithm classifications for MCI in a population-based sample, the rates of reversion to normal varied from $18 \%$ to $45 \%$ across the range of diagnoses indicating pathological decline; but in other studies using algorithm diagnoses, the reversion rate was as high as $93 \% .{ }^{33}$ These studies suggest that longitudinal outcomes may differ based on the diagnostic criteria applied and whether an algorithm versus a consensus conference approach is used.'

Limitations of ADAMS include possible response bias due to selective nonparticipation and attrition. This is a potential risk for all longitudinal studies, especially epidemiological studies of older individuals where comorbidities and mortality are common. To minimize response bias, we used archived information from prior interviews to develop response propensity models and associated weighting adjustments. Due to the relatively small sample size in some age groups, the estimates of incidence lack some precision. Also, due to the relatively small numbers in any given geographic region, we could not assess regional differences in outcomes. The higher rate of attrition for the Hispanic group may limit the generalizability of the results for that ethnic group. Diagnostic errors may have occurred due to inaccuracies in both the diagnostic criteria and in the assignment of the diagnosis by the consensus panel. The diagnostic criteria particularly for cognitive impairment without dementia are in the developmental stages and require further validation. ${ }^{11,34}$ We attempted to minimize variability in the assignment of the clinical diagnosis within this study by using assessment teams based at a single site who used methods established in previous epidemiological studies and by using 1 common expert case review panel.

Our findings show that combined dementia and CIND affect a very large segment of the elderly population. Those with CIND are at particularly high risk of progressing to dementia; however, at least within a 6-year period, not all individuals with CIND progress to dementia. Our estimates of national incidence rates for CIND and dementia may serve as a benchmark against which to measure the effectiveness of potential future dementia prevention interventions.

\section{Acknowledgment}

Funding for this project was from the National Institute on Aging (U01 AG09740, D.R.W., principal investigator; R01 AG027010, K.M.L., principal investigator).

We thank the ADAMS participants and the research staff at Duke University Medical Center and the University of Michigan.

\section{Potential Conflicts of Interest}

B.L.P.: grant support, NIH; travel support, NIH; payment for writing/reviewing manuscript, NIH. K.M.L.: grant support, NIH; travel support, NIH; payment for writing/ reviewing manuscript, NIH. R.J.M.: grant support, NIH; travel support, NIH; payment for writing/reviewing manuscript, NIH; writing assistance/medicines/equipment/administrative support, NIH. G.G.F.: grant support, $\mathrm{NIH}$; travel support, NIH; payment for writing/reviewing manuscript, NIH. G.G.P.: grant support, NIH; travel support, NIH; payment for writing/reviewing manuscript, NIH. J.R.B.: grant support, NIH; payment for writing/ reviewing manuscript, NIH. D.C.S.: grant support, NIH. N.L.F.: honorarium, NIH; travel support, NIH; board membership, Myriad Pharmaceuticals, Bristol-Myers Squibb; consultancy, GE Healthcare, Wyeth/Elan Pharmaceuticals, Janssen Alzheimer Immunotherapy, NIH Center for Scientific Review, Academy of Finland; grants/grants pending, Pfizer, Baxter Bioscience, Janssen Alzheimer Immunotherapy, Eli Lilly, Wyeth/Elan Pharmaceuticals, Merck, Myriad Genetics, Eisai; speaking fees, MK Medical Communications, Society of Nuclear Medicine, Mt. Sinai Medical Center (Miami FL), St. John's Medical Center (Jackson WY). B.G.: grants/grants pending, NIH; travel support, NIH; payment for writing/reviewing manuscript, NIH. F.W.U.: grant support, NIH; honorarium, Duke University; travel support, NIH; consultancy, Eli Lilly; stock/stock options, Eli Lilly. K.A.W.-B.: grant support, NIH; travel support, NIH; payment for writing/reviewing manuscript, NIH; speaking fees, Medivation, Elan Corporation/Wyeth; patents, US Patent 6867236 (issued 2005) Nonsteroidal anti-inflammatory drugs for treatment of $\mathrm{AD}$; royalties, publication of text: Geriatric Neuropsychology (Guildford Pub 2006); unpaid scientific advisory board, Zinfandel Pharmaceutical. S.G.H.: grant support, NIH; travel support, NIH; fees for participation in review activities, NIH; payment for writing/reviewing manuscript, NIH. D.R.W.: grant support, NIH; travel support, NIH; payment for writing/ reviewing manuscript, NIH. R.B.W.: grant support, NIH; travel support, NIH.

\section{References}

1. Brookmeyer R, Johnson E, Ziegler-Graham K, Arrighi HM. Forecasting the global burden of Alzheimer's disease. Alzheimers Dement 2007;3:186-191.

2. Miech RA, Breitner JCS, Zandi PP, et al. Incidence of AD may decline in the early 90's for men, later for women: The Cache County Study. Neurology 2002;58:209-217.

3. Kukull WA, Higdon R, Bowen JD, et al. Dementia and Alzheimer disease incidence: a prospective cohort study. Arch Neurol 2002; 59:1737-1746. 
4. Ganguli M, Dodge HH, Chen $\mathrm{P}$, et al. Ten-year incidence of dementia in a rural elderly US community population: the MoVIES Project. Neurology 2000;54:1109-1116.

5. Hendrie HC, Ogunniyi A, Hall KS, et al. Incidence of dementia and Alzheimer disease in 2 communities: Yoruba residing in lbadan, Nigeria, and African Americans residing in Indianapolis, Indiana. JAMA 2001;285:739-747.

6. Bachman DL, Wolf PA, Linn RT, et al. Incidence of dementia and probable Alzheimer's disease in a general population: The Framingham Study. Neurology 1993;43:515-519.

7. Evans DA, Bennett DA, Wilson RS, et al. Incidence of Alzheimer disease in a biracial urban community. Arch Neurol 2003;60: 185-189.

8. Kawas C, Gray S, Brookmeyer R, et al. Age-specific incidence rates of Alzheimer's disease: the Baltimore Longitudinal Study of Aging. Neurology 2000;54:2072-2077.

9. Unverzagt FW, Sujuan G, Lane KA, et al. Mild cognitive dysfunction: an epidemiological perspective with an emphasis on African Americans. J Geriatr Psychiatry Neurol 2007;20:215-226.

10. Plassman $\mathrm{BL}$, Langa KM, Fisher GG, et al. Prevalence of cognitive impairment without dementia in the United States. Ann Intern Med 2008;148:427-434.

11. Winblad $B$, Palmer $K$, Kivipelto $M$, et al. Mild cognitive impairment-beyond controversies, towards a consensus: report of the International Working Group on Mild Cognitive Impairment. J Intern Med 2004;256:240-246.

12. Unverzagt FW, Ogunniyi A, Taler $V$, et al. Incidence and risk factors for cognitive impairment no dementia and mild cognitive impairment in African Americans. Alzheimer Dis Assoc Disord (Epub ahead of print).

13. Solfrizzi V, Panza F, Colacicco AM, et al. Vascular risk factors, incidence of $\mathrm{MCl}$, and rates of progression to dementia. Neurology 2004;63:1882-1891.

14. Manly JJ, Tang MX, Schupf N, et al. Frequency and course of mild cognitive impairment in a multiethnic community. Ann Neurol 2008;63:494-506

15. Caracciolo B, Palmer K, Monastero R, et al. Occurrence of cognitive impairment and dementia in the community: a 9-year-long prospective study. Neurology 2008;70:1778-1785.

16. Juster FT, Suzman R. An overview of the Health and Retirement Study. J Hum Resour 1995;30(suppl):135-145.

17. Willis RJ. Theory confronts data: how the HRS is shaped by the economics of aging and how the economics of aging will be shaped by the HRS. Labour Econ 1999;6:119-145.

18. Soldo BJ, Hurd MD, Rodgers WL, Wallace RB. Asset and health dynamics among the oldest old: an overview of the AHEAD study. J Gerontol B Psychol Sci Soc Sci 1997;52 Spec No:1-20.
19. Documentation of cognitive functioning measures in the Health and Retirement Study. University of Michigan, 2005. Available at: http://hrsonline.isr.umich.edu/docs/userg/dr-006.pdf Accessed December 14, 2007

20. Jorm AF. A short form of the Informant Questionnaire on Cognitive Decline in the Elderly (IOCODE): development and cross-validation. Psychol Med 1994;24:145-153.

21. Aging, Demographics and Memory Study (ADAMS). Sample design, weights, and analysis for ADAMS. 2006. Available at: http://hrsonline.isr.umich.edu/sitedocs/userg/ADAMSSample Weights_Jun2009.pdf Accessed February 14, 2010.

22. Langa KM, Plassman BL, Wallace RB, et al. The Aging, Demographics, and Memory Study: study design and methods. Neuroepidemiology 2005;25:181-191

23. The Health and Retirement Study. Available at: http://hrsonline. isr.umich.edu/ Accessed December 14, 2007.

24. American Psychiatric Association. Diagnostic and statistical manual of mental disorders. 3rd ed rev. Washington, DC: American Psychiatric Association, 1987.

25. American Psychiatric Association. Diagnostic and statistical manua of mental disorders. 4th ed. Washington, DC: American Psychiatric Association, 1994

26. McKhann G, Drachman D, Folstein M, et al. Clinical diagnosis of Alz heimer's disease: report of the NINCDS-ADRDA Work Group under the auspices of the Department of Health and Human Services Task force on Alzheimer's disease. Neurology 1984;34:939-944.

27. Roman GC, Tatemichi TK, Erkinjuntti T, et al. Vascular dementia: diagnostic criteria for research studies. Report of the NINDSAIREN International Workshop. Neurology 1993;43:250-260.

28. Plassman $\mathrm{BL}$, Khachaturian AS, Townsend JJ, et al. Comparison of clinical and neuropathological diagnoses of $A D$ in three epidemiological samples. Alzheimer Dement 2006;2:2-11.

29. Canadian Study of Health and Aging Working Group.The incidence of dementia in Canada. Neurology 2000;55:66-73.

30. Arias E. United States life tables, 2004. Natl Vital Stat Rep 2007 $56: 1-39$.

31. Matthews FE, Stephan BC, McKeith IG, et al. Two-year progression from mild cognitive impairment to dementia: to what extent do different definitions agree? J Am Geriatr Soc 2008;56:1424-1433.

32. Tschanz JT, Welsh-Bohmer KA, Lyketsos CG, et al. Conversion to dementia from mild cognitive disorder: the Cache County Study. Neurology 2006;67:229-234

33. Ritchie K, Artero S. Classification criteria for mild cognitive impairment. Neurology 2001;56:37-42.

34. Matthews FE, Stephan BCM, Bond J, et al. Operationalisation of mild cognitive impairment: a graphical approach. PLoS Med 2007 4:1615-1619. 